\title{
Valorization of lignocellulosic biomass by selective solvolysis reaction for production of sugar and phenolic platform chemicals
}

\author{
Junming Xu*a,b, Qiaolong Zhai ${ }^{\mathrm{a}}$,Xinfeng Xie ${ }^{\mathrm{c}}$, Jianchun Jiang ${ }^{\mathrm{a}, \mathrm{b}}$, Todd F. Shupe ${ }^{\mathrm{d}}$ \\ a Institute of Chemical Industry of Forest Products, Chinese Academy of Forestry; Key Lab. of Biomass Energy and Material, \\ Jiangsu Province; National Engineering Lab. for Biomass Chemical Utilization; Key and Open Lab. on Forest Chemical \\ Engineering, SFA, Nanjing 210042, China \\ ${ }^{\mathrm{b}}$ Co-Innovation Center of Efficient Processing and Utilization of Forest Resources, Nanjing Forestry University \\ c. School of Forest Resources and Environmental Science, Michigan Technological University. Houghton, MI 49931, US. \\ ${ }^{d}$ Wood Science Consulting, LLC Baton Rouge, Louisiana 70816, United States \\ *Corresponding authors: E-mail address: xujunming@icifp.cn
}

\section{Supplementary Information}

The moisture content of biomass was determined by drying biomass at $105^{\circ} \mathrm{C}$ overnight followed by cooling in a desiccator for $2 \mathrm{~h}$. For each sample, this analysis was repeated at least three times.

For the determination of the ash content, ca. $100 \mathrm{mg}$ of pulp or starting material were placed in a quartz crucible. The samples were then burned in a ventilated muffle oven under a controlled temperature program: room temperature to $450{ }^{\circ} \mathrm{C}$ at $7{ }^{\circ} \mathrm{C} \mathrm{min}^{-1} ; 450$ to $750^{\circ} \mathrm{C}$ at $2.5^{\circ} \mathrm{C} \mathrm{min}^{-1}$; and $750^{\circ} \mathrm{C}$ for $2 \mathrm{~h}$. In sequence, the crucibles were quenched to room temperature in a desiccator. The ash was weighted. For each sample, this analysis was repeated at least three times.

Before conducting compositional analysis, $2 \mathrm{~g}$ of each biomass sample was extracted with an ethanol/benzene mixture ( $4: 1 \mathrm{v} / \mathrm{v}, 40 \mathrm{~mL})$ using solvents extractor. Each extraction was conducted at boiling point of ethanol for $30 \mathrm{~min}$. After each extraction, the liquid was removed by filtration. The extracted biomass samples were dried at $105^{\circ} \mathrm{C}$ overnight and placed in a desiccator for $2 \mathrm{~h}$ before use.

The content of sugar derivatives (including glucans, xylans) and lignin were determined by acid saccharification. Typically, $50.0 \mathrm{mg}$ of ground and sieved sample $(500 \mu \mathrm{m})$ was suspended in a $72 \%$ sulfuric acid solution $(0.5 \mathrm{~mL})$ under stirring at $38{ }^{\circ} \mathrm{C}$ for $5 \mathrm{~min}$. In sequence, $10 \mathrm{~mL}$ of distilled water was added into the suspension. The saccharification was then conducted under stirring at $130{ }^{\circ} \mathrm{C}$ for $1.5 \mathrm{~h}$. The suspension was left to cool down to room temperature. The suspension was filtered. The filtrate was analyzed by HPLC.

Table S1 Overall design of selective solvolysis.

\begin{tabular}{lll}
\hline Materials & Reaction conditions & Sample tests \\
\hline Model compounds a ${ }^{2}$ & $\begin{array}{l}\text { Detailed parameters including reaction } \\
\text { temperature and time were tested }\end{array}$ & $\begin{array}{l}\text { GC-MS analysis for each sample to } \\
\text { determine changes in molecular } \\
\text { structure of sugars }\end{array}$ \\
Bamboo & $\begin{array}{l}\text { Detailed parameters including reaction } \\
\text { temperature and time }\end{array}$ & $\begin{array}{l}\text { Both liquid and solid products were } \\
\text { characterized }\end{array}$
\end{tabular}

${ }^{a}$ Model compounds includes xylose, glucose, and cellulose. 
The determination of the sugar and derivatives content was performed on an HPLC Shimadzu LC-20AB equipped with an Aminex HPX-87H. The analyses were carried out at $65{ }^{\circ} \mathrm{C}$ using a $5 \mathrm{mM} \mathrm{H}_{2} \mathrm{SO}_{4}$ solution as eluent $\left(0.5 \mathrm{~mL} \mathrm{~min}^{-1}\right)$.
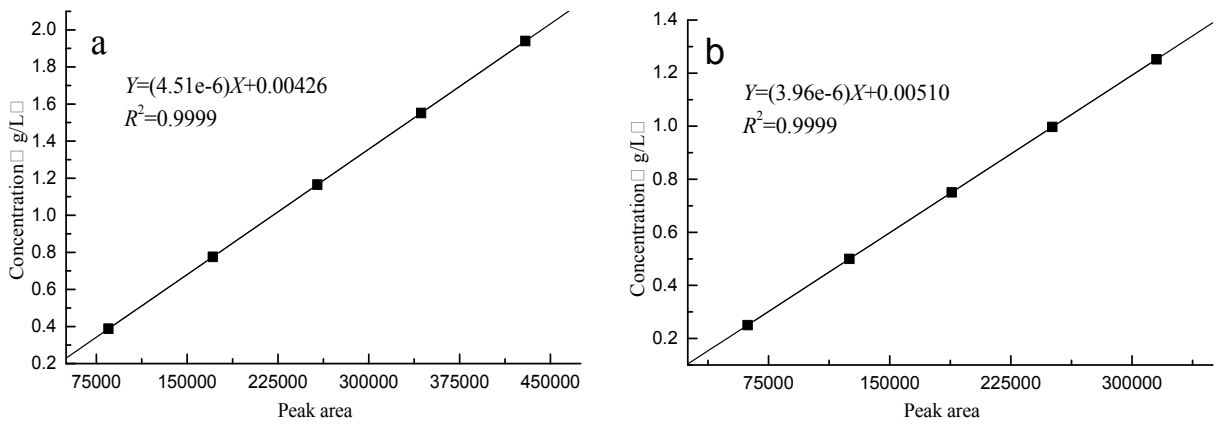

a. methyl- $\alpha$-D-xylofuranoside,; b. methyl- $\alpha$-D-galactopyranoside

Fig.S1 The standard curve of concentration of methyl- $\alpha$-D-xylofuranoside, methyl- $\alpha$-D-galactopyranoside.

For the determination of the lignin content, the same saccharification procedure was used; however, the determination initiates with $500 \mathrm{mg}$ of sample and scaled up the volume of sulfuric acid solution and water to $5 \mathrm{~mL}$ and $100 \mathrm{~mL}$, respectively. After the saccharification at $130{ }^{\circ} \mathrm{C}$ for $1.5 \mathrm{~h}$, the reaction mixture was filtered on a filter previously weighted. The solid was washed with distilled water until neutral $\mathrm{pH}$. The solid was dried in a ventilated oven at $60^{\circ} \mathrm{C}$ for $1-2$ days. The weight of this dried solid was considered as the residual lignin in the carbohydrate fraction.

Table S2 Decomposition behavior of the methyl- $\alpha$-glucoside in different reaction parameters

\begin{tabular}{cccccc}
\hline & & & & \multicolumn{3}{c}{ Byproducts } \\
Catalyst & $\begin{array}{c}\text { Reaction } \\
\text { temperature }{ }^{\circ} \mathrm{C}\end{array}$ & $\begin{array}{c}\text { Reaction } \\
\text { time/min }\end{array}$ & Conversion/\% & $\begin{array}{c}\text { 5-Methoxymethyl } \\
\text { furfural/\% }\end{array}$ & $\begin{array}{c}\text { Methyl } \\
\text { levulinate/\% }\end{array}$ \\
\hline $3 \% \mathrm{H}_{2} \mathrm{SO}_{4}$ & 240 & 10 & 100 & 31 & 57 \\
$3 \% \mathrm{H}_{2} \mathrm{SO}_{4}$ & 200 & 10 & 11 & 2 & 7 \\
$3 \% \mathrm{H}_{2} \mathrm{SO}_{4}$ & 180 & 40 & 67 & 13 & 46 \\
$3 \% \mathrm{H}_{2} \mathrm{SO}_{4}$ & 180 & 10 & 6 & - & - \\
$3 \% \mathrm{H}_{2} \mathrm{SO}_{4}$ & 160 & 40 & 59 & 27 & 32 \\
$3 \% \mathrm{H}_{2} \mathrm{SO}_{4}$ & 160 & 10 & 5 & - & - \\
$3 \% \mathrm{H}_{2} \mathrm{SO}_{4}$ & 140 & 40 & 27 & 13 & 15 \\
$3 \% \mathrm{H}_{2} \mathrm{SO}_{4}$ & 140 & 10 & 5 & - & - \\
$\mathrm{No} \mathrm{catalyst}_{3 \% \mathrm{H}_{2} \mathrm{SO}_{4}}^{140}$ & 120 & 40 & 5 & 3 & 2 \\
$3 \% \mathrm{H}_{2} \mathrm{SO}_{4}$ & 120 & 10 & 2 & - & 2 \\
$\mathrm{No} \mathrm{catalyst}$ & 120 & 40 & 0 & - & - \\
\hline
\end{tabular}

All the experiment were carried out at the mass ratio of $\mathrm{m}($ methyl- $\alpha$-glucoside $): \mathrm{m}($ methanol $)=1: 7$ -: not detected 
Table S3 Decomposition behavior of the methyl $\alpha$-D-xylopyranoside in different reaction parameters.

\begin{tabular}{|c|c|c|c|c|c|}
\hline Catalyst & $\begin{array}{c}\text { Reaction } \\
\text { temperature } /{ }^{\circ} \mathrm{C}\end{array}$ & $\begin{array}{l}\text { Reaction } \\
\text { time/min }\end{array}$ & Conversion/\% & furfural $/ \%$ & $\begin{array}{l}\text { Byproducts } \\
\beta \text {-methoxy-2-furanethanol /\% }\end{array}$ \\
\hline $3 \% \mathrm{H}_{2} \mathrm{SO}_{4}$ & 200 & 10 & 92 & 8 & 40 \\
\hline $3 \% \mathrm{H}_{2} \mathrm{SO}_{4}$ & 180 & 40 & 100 & 13 & 46 \\
\hline $3 \% \mathrm{H}_{2} \mathrm{SO}_{4}$ & 180 & 10 & 57 & 5 & 37 \\
\hline $3 \% \mathrm{H}_{2} \mathrm{SO}_{4}$ & 160 & 40 & 45 & 7 & 32 \\
\hline $3 \% \mathrm{H}_{2} \mathrm{SO}_{4}$ & 160 & 10 & 26 & 3 & 19 \\
\hline $3 \% \mathrm{H}_{2} \mathrm{SO}_{4}$ & 140 & 40 & 28 & 5 & 20 \\
\hline $3 \% \mathrm{H}_{2} \mathrm{SO}_{4}$ & 140 & 10 & 18 & - & 11 \\
\hline No catalyst & 140 & 40 & 5 & - & 2 \\
\hline $3 \% \mathrm{H}_{2} \mathrm{SO}_{4}$ & 120 & 40 & 17 & 3 & 9 \\
\hline $3 \% \mathrm{H}_{2} \mathrm{SO}_{4}$ & 120 & 10 & 3 & - & - \\
\hline No catalyst & 120 & 40 & 0 & - & - \\
\hline
\end{tabular}

Model compounds, acid catalyst and solvent (methanol) were placed in a $250 \mathrm{~mL}$ autoclave and heated to the desired temperature $\left(120-200{ }^{\circ} \mathrm{C}\right)$ under mechanical stirring. The reaction proceeded under autogeneous pressure for 10-40 min. In sequence, the mixture was left to cool down to room temperature. The liquor was separated from the solids (residue) by filtration through a paper filter.

The absolute contents of 5-methoxymethyl furfural (MMF) and methyl levulinate (MLA) in the liquefaction products were determined by using n-octanol as a reference in the $\mathrm{GC}$ analysis. The peak area ratio of MLA and n-octanol reflects the content ratio according to the standard curve $(y=2.06543 x-0.02107, R 2=0.99998)$. Similarly, the peak area ratio of MMF and n-octanol reflects the content ratio, according to the standard curve $(y=1.9657 x+0.0612, R 2=0.9996)$.

Bamboo biomass (40 g), sulfuric acid (1-2 g, $98 \%$ ) and solvent $(300 \mathrm{~mL})$ were placed in a $1000 \mathrm{~mL}$ autoclave and heated to the desired temperature $\left(120-220{ }^{\circ} \mathrm{C}\right)$ under mechanical stirring. The reaction proceeded under autogeneous pressure for $10 \mathrm{~min}$. In sequence, the mixture was left to cool down to room temperature. The liquor was separated from the solids (Residue) by filtration. The phenol products were precipitated by adding a certain amount of water stepwisely. Further separation of the solid phenolic products was carried out by centrifugal separation at 6000 $\mathrm{r} / \mathrm{min}$. Yield of methyl monosaccharides was obtained by separating the solvent using a rotary evaporator.

The phenolic products and sugar derivatives were analyzed using GC-MS, and the results are shown in Table S4. GC-MS of the decomposed phenolic compounds obtained selective liquefaction method in methanol at $200{ }^{\circ} \mathrm{C}$. SI stands for similarity index obtained from the comparison with the MS libraries NIST 08, NIST 08s, and Wiley 9. STD stands for external standard (di-n-butyl ether). 
Table S4 The GC-MS components of phenolic products.

\begin{tabular}{lllll}
\hline R.T & & \multicolumn{4}{l}{ Area $(\%)^{\text {a }}$} & \\
\cline { 3 - 5 }$(\min )$ & Identification by GC-MS & $1 \#$ & $2 \#$ & $3 \#$ \\
\hline & Phenolic compounds & $\mathbf{8 8 . 9 4}$ & $\mathbf{8 5 . 1 6}$ & $\mathbf{8 6 . 6 5}$ \\
10.67 & 2-Methyl-phenol & 3.73 & -- & 8.32 \\
12.08 & 4-Propyl-phenol & 1.65 & 2.86 & 5.04 \\
13.47 & Guaiacol & 5.66 & 5.70 & 8.73 \\
16.69 & 3-Methyl-guaiacol & -- & 4.32 & 7.28 \\
18.09 & 4-Methoxy-guaiacol & 8.33 & 10.26 & 15.64 \\
19.46 & Catechol & 4.86 & 18.87 & 5.76 \\
20.27 & 4-Propyl-2,6-dimethoxyphenol & 2.73 & 7.56 & 4.45 \\
20.95 & 4-Hydroxy-3-methoxyphenyl-2-ethanol & 10.58 & 6.38 & 7.68 \\
23.66 & 2-methoxy-4-acetone-phenol & 13.37 & 8.74 & -- \\
25.39 & Vanillin & 5.52 & -- & 10.34 \\
26.47 & 4-(3'-methoxy-4'-hydroxy)-phenyl-2-carboxyl & 7.65 & 8.46 & 7.98 \\
29.80 & 4-(3'-methoxy-4'-hydroxy)-phenyl-2-butenoat & 5.88 & 3.74 & -- \\
30.62 & Apocynol & 2.36 & 1.26 & -- \\
31.52 & 4-Methoxy-2-hydroxybenzoate & 6.22 & 5.76 & 5.43 \\
33.51 & Phenolic dimers & 2.74 & 1.25 & -- \\
& Others & 7.33 & 6.66 & 6.96 \\
7.39 & 2-Methoxy-furan & -- & -- & 1.52 \\
8.17 & 1,1,3-Trimethyl-cyclohexane & -- & -- & 2.34 \\
10.94 & 3-Methyl-cyclohexane & 1.44 & 2.23 & 1.87 \\
17.64 & 2-Naphthalenecarboxylic acid methyl ester & -- & 0.69 & -- \\
25.60 & 1-Methylene-3-(1-methylethenyl)-cyclohexan & 0.79 & -- & 1.23 \\
25.75 & 2,5-Dimethyl-2,4-hexadiene & 2.35 & 0.99 & -- \\
28.85 & 1,1'1"-(1-ethanyl-2-ylidene)-tris-Benzene & 2.75 & 1.45 & -- \\
31.65 & 1,2-Dimethoxy-4-(3-methoxy-1-propenyl)ben & -- & 1.30 & -- \\
& All unknown compounds & 3.73 & 8.18 & 6.39 \\
\hline
\end{tabular}

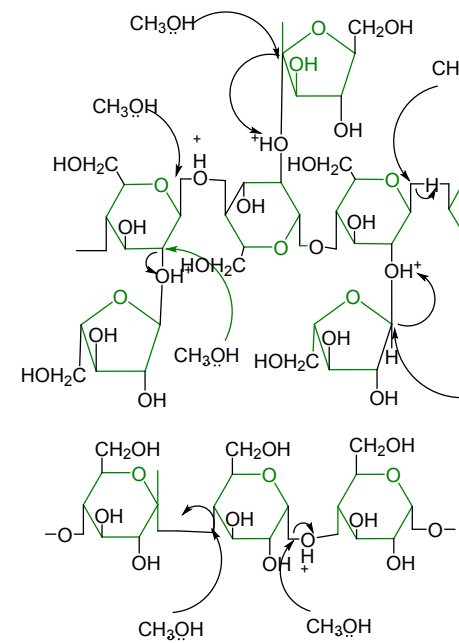

Holocellulose

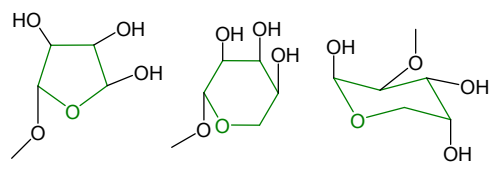<smiles>COC1OC(CO)C(O)C(O)C1O</smiles><smiles>COC(=O)C1OC(OC)C(O)C(O)C1OC</smiles><smiles>COC1OC(CO)C(O)C(O)C1O</smiles><smiles>COC1OC(CO)C(O)C(O)C1O</smiles>

methyl monosaccharides 

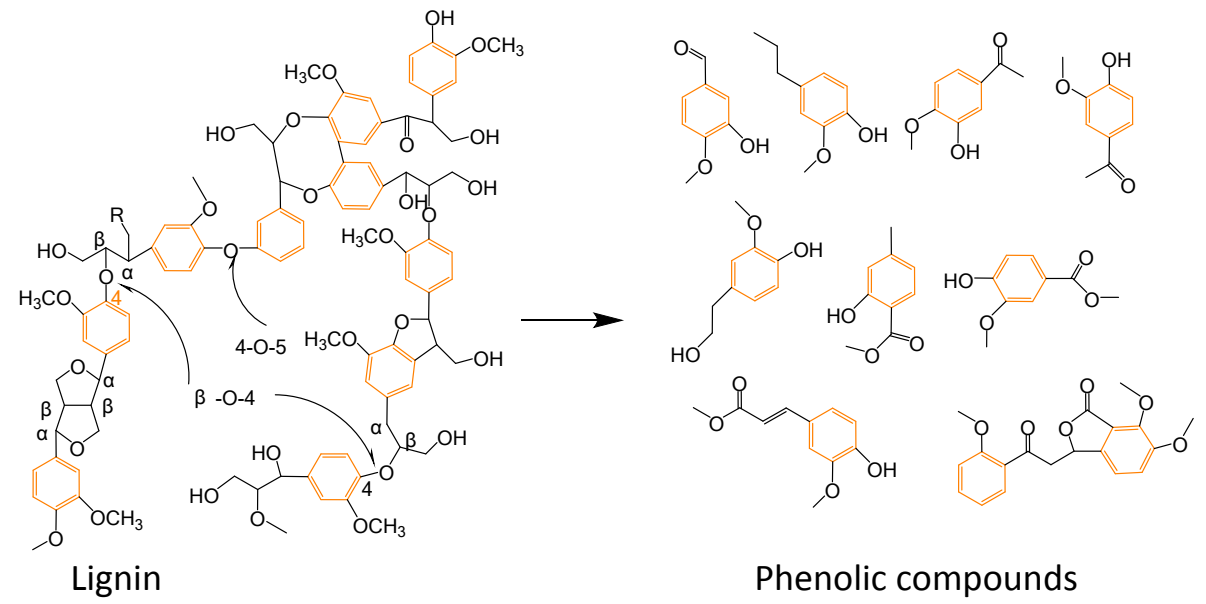

Phenolic compounds

Fig. S2 Proposed decomposition mechanism of holocellulose and lignin in methanol medium with $\mathrm{H}_{2} \mathrm{SO}_{4}$ as catalyst.

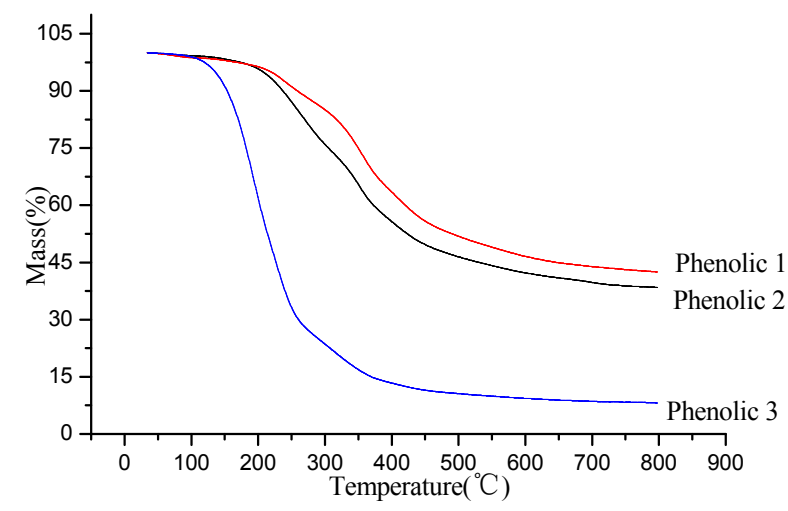

Fig. S3 TGA results of the phenolic products generated from solvolysis at $180^{\circ} \mathrm{C}$

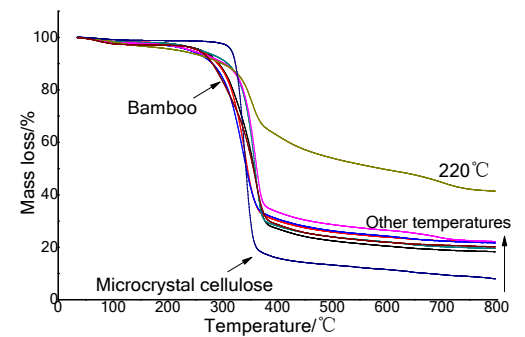

Fig. S4 TG curves in nitrogen atmosphere (Commercial microcrystalline cellulose, bamboo biomass, and the residue after solvolysis process at different temperatures) 
TG curves for Phenolic 1, 2, 3 subjected to sulfuric acid catalyst at $180{ }^{\circ} \mathrm{C}$ for $10 \mathrm{~min}$. Considering the polymeric nature of this material, this weight loss is associated with the release of volatile fragments generated by lignin thermolysis rather than vaporization of low $\mathrm{Mw}$ components eventually occurring in the solid lignin.

TG curves for residue obtained from catalytic bio-refining in methanol under the catalysis of sulfuric acid at different temperatures for $10 \mathrm{~min}$. All the samples were operated at Netzsch409PC from room temperature to $600{ }^{\circ} \mathrm{C}$ with a heating rate of $5{ }^{\circ} \mathrm{C} / \mathrm{min}$ under a flow of $50 \mathrm{~mL} / \mathrm{min}$ of nitrogen. 